\title{
Resistencias sociales y ecosistémicas: trayectorias agroecológicas en la horticultura de Mendoza, Argentina
}

\author{
Jorge Daniel Ivars \\ Instituto de Ciencias Humanas, Sociales y Ambientales \\ (INCIHUSA-CCT Mendoza). CONICET. Universidad \\ Nacional de Cuyo, Argentina \\ jorgedanielivars@gmail.com \\ Oscar Alberto Carballo Hiramatsu \\ Instituto de Ciencias Humanas, Sociales y Ambientales \\ (INCIHUSA-CCT Mendoza). CONICET., Argentina \\ ocarballo@mendoza-conicet.gob.ar \\ Juan Pablo Fili \\ Instituto de Ciencias Humanas, Sociales y Ambientales \\ (INCIHUSA-CCT Mendoza). CONICET. Universidad \\ Nacional de Cuyo, Argentina \\ juanpablofilicarrizo@gmail.com
}

Social and ecosystem resistances: agro-ecological trajectories in horticulture in Mendoza, Argentina

\section{Resumen:}

En el presente trabajo nos proponemos describir los saberes agroculturales que aplican los horticultores campesinos de los oasis norte y centro de Mendoza y analizar procesos de ruptura agroecológica. Se utilizaron técnicas cualitativas para dar cuenta de los sentidos que los horticultores dan a su trabajo y al entorno que sienten, perciben y modifican. Los saberes dominantes se imponen a través de una aparente falta de alternativas, mientras que las rupturas agroecológicas plantean una alternativa a través de una síntesis de saberes concretos y abstractos. La organización y la acción colectiva promueven y consolidan la agroecología que favorece el despliegue de una base de recursos que sinergiza el trabajo humano y la tierra viva.

Palabras ClaVe: Agroecología, Saberes, Horticultura, Resistencias, Mendoza.

\section{Abstract:}

In this paper we propose to describe the agro-cultural knowledge applied by the peasant horticulturists from the northern and central oases of Mendoza and to analyze the processes of agro-ecological rupture. Qualitative techniques were used to give an account of the senses that the horticulturists give to their work and to the environment they feel, perceive and modify. The dominant knowledge is imposed through an apparent lack of alternatives, while the agroecological ruptures propose an alternative through a synthesis of concrete and abstract knowledge. Organization and collective action promote and consolidate agroecology that favors the deployment of a resource base that synergizes human work and living land.

KeYwORDS: Agroecology, Knowings, Horticulture, Resistance, Mendoza.

\section{INTRODUCCIÓN}

En las últimas décadas el agro argentino sufrió una reconfiguración de una intensidad pocas veces vista. La apertura y desregulación económica, así como la desactivación de numerosos mecanismos de los que disponía el Estado, tendientes a compensar desigualdades, impusieron un nuevo modelo de funcionamiento basado en el predominio del capital financiero y en una inherente tendencia a la concentración de las unidades 
productivas (Giarracca y Teubal, 2017). La producción hortícola en la provincia de Mendoza fue ajena a estas transformaciones. En este contexto se evidenció un acentuado proceso de transformación de su base técnica y al mismo tiempo la desaparición de miles de explotaciones y la concentración de la actividad en unidades de mayores dimensiones (Carballo Hiramatsu, 2019). De este modo, nos proponemos dos objetivos: describir los saberes subyacentes a las prácticas productivas de los horticultores campesinos en relación a los cambios técnicos observados, con especial atención a las formas de aceptación e imposición de los mismos, y analizar luego algunos procesos de ruptura y fenómenos que incidieron y favorecieron el desarrollo de prácticas agroecológicas.

Como puede observarse, este planteo implica, necesariamente, partir de algunas consideraciones acerca del conocimiento agronómico que ponen en juego los horticultores en sus labores agroculturales cotidianas. En este sentido, y en términos generales, Toledo y Barrera Bassols (2008) postulan que el conjunto de saberes que existe actualmente en relación a la agricultura podría ser englobado, si se sigue la propuesta de Levi-Strauss, en dos tradiciones intelectuales:

Por un lado, una forma de "conocimiento tradicional", que se remonta a la aparición de la práctica de la agricultura hace unos 10.000 años, y que está basado en un conocimiento ecológico anclado localmente, de carácter diacrónico y colectivo, y ligado a una visión holística de la vida. Este conocimiento es una síntesis de experiencias acumuladas históricamente y transmitidas tanto comunitariamente como de generación en generación, junto con la experiencia personal adquirida con la repetición de los ciclos productivos y enriquecida "por variaciones, eventos imprevistos y sorpresas diversas" (p. 73). En términos más generales es definida por Villoro (2009) como "sabiduría", en la medida en que no se basa en tratados científicos fundamentados en métodos replicables, sino en "la observación personal, el trato frecuente por otros hombres, el sufrimiento y la lucha, el contacto con la naturaleza, la vivencia intensa de la cultura" (Villoro, 2009, p. 226) ${ }^{1}$.

Por otro lado, ubican a la "ciencia moderna", cuya emergencia se remonta a apenas 300 años con la conformación de las primeras agrupaciones científicas europeas. Esta forma de conocimiento resulta inseparable del desarrollo del capitalismo, y queda habitualmente subordinada no solo a su inherente lógica maximizadora de la producción, sino a los intereses de las clases dominantes. Bajo la racionalidad económica y tecnológica del capitalismo, los objetivos de la ciencia moderna en la agricultura van a enfocarse en "tratar de alinear a la producción agrícola con la producción industrial: simplificar, estandarizar, y acelerar sus procesos naturales tanto como sea posible" (Bernstein, 2012, p. 126). Esta subordinación se vio magnificada con el advenimiento de la llamada "petroagricultura", la cual colocó a la industria química en una posición dominante en la producción agrícola (Walker, 2004). Bajo este paradigma el conocimiento tradicional pasó a ser sinónimo de atraso.

Sin embargo, como señala Jean van der Ploeg (2010), sería incorrecto asumir que las ciencias agronómicas siempre estuvieron vinculadas de modo tan directo a las necesidades empresariales. El autor rescata la autonomía que caracterizó a los científicos en los albores de la introducción de productos químicos industriales a la agricultura. Ello queda reflejado en la independencia con la que encaraban sus estudios, pero también en la postura crítica y de advertencia que adoptaban frente a las prácticas comerciales promovidas por la industria. Esta autonomía científica se fue erosionando a medida que el capital buscó exprimir la producción de conocimiento como forma de relanzar la decreciente tasa de ganancia (Mandel, 1995). Si seguimos a van der Ploeg, el capital necesita que la ciencia genere nuevas promesas de riquezas sobre las cuales atraer más capital, "y las necesita desesperadamente" (Ploeg, 2010, p. 254). Aquí revisten vital importancia las expectativas que pueda generar el conocimiento científico aplicado: "grandes programas de investigación (...) dedicados a la exploración de nuevas posibilidades tecnológicas (...) la búsqueda de nuevas formas de ingeniería alimentaria y la reconstrucción de la naturaleza mediante la biotecnología” (Ploeg, 2010, p. 357). Para este autor "la promesa de los nuevos El Dorado es uno de tantos vínculos que atan actualmente a partes considerables de la ciencia” (Ploeg, 2010, p. 358) con el capital. 
Es bajo estos imperativos que debemos comprender lo que Jean van der Ploeg (1993) denomina proceso de cientificación (p. 153). Es decir, la "reconstrucción sistémica de las actuales prácticas agrícolas según las pautas marcadas por diseños de carácter científico” (Ploeg, 1993, p. 153). Bajo este proceso no solo opera una creciente subsunción real del proceso de trabajo agrícola, cada vez más dependiente de bienes provistos por la industria, sino también un "régimen de verdad" (Foucault, 2007), al que se acoplan un conjunto de prácticas agroculturales que "divide lo verdadero de lo falso" (Foucault, 2007, p. 37). En esta precisa división se evidencia un "dispositivo de saber-poder", que delimita la forma correcta de practicar la agricultura, no solo desde el conocimiento "experto" sobre la producción, sino también desde el consumo y la circulación.

Esta aproximación que surge del vínculo ciencia-capital genera, voluntaria e involuntariamente, un deterioro y un direccionamiento de los saberes de los diferentes sujetos involucrados en la producción, difusión y aplicación de estos conocimientos sobre agricultura. En palabras de Ploeg (2010, p. 39), genera tanto "conocimiento como ignorancia". En este sentido, consideraremos el vínculo ciencia-capital como una dupla de saber-poder a partir de la cual analizamos las formas y grados de aceptación de estos conocimientos por parte de los campesinos, y las formas en que se producen los cuestionamientos y rupturas con los mismos. Landini (2011) describe estos fenómenos de ruptura no como un retorno a lo que Toledo y Barrera-Bassols (2014) denominan conocimiento tradicional, sino como un movimiento de síntesis fruto de la combinación de saberes locales y conocimiento científico. En este sentido, esta ruptura evidenciaría una "sustracción de las relaciones de fuerza establecidas como saberes constituidos" (Deleuze, 1999, p. 157), que se contraponen a la dupla saber-poder dominante. Las condiciones para que estas experiencias prosperen siempre se dan a la par de procesos de construcción colectiva por los cuales circulan, propagan y resignifican tanto los conocimientos como los medios necesarios para la producción y sus productos.

\section{ConSIDERACIONES METODOLÓgiCAS}

Respecto de la estrategia metodológica adoptada, el presente trabajo constituye un estudio de caso (Stake, 1995; Yin, 1994) enmarcado en el paradigma interpretativo de investigación (Vasilachis de Gialdino, 2006). En este sentido, las técnicas de producción y generación de la información primaria de carcter cualitativo fueron, fundamentalmente, entrevistas en profundidad (Kvale, 1996; Taylor y Bogdan, 1992) y muy frecuentes visitas a campo que dieron como resultado cerca de 50 entrevistas a productores hortícolas e informantes clave entre los aos 2012 y 2020 en el Oasis Norte y Centro (Valle de Uco) de la provincia de Mendoza.

Las entrevistas se realizaron en el marco de dos trabajos de investigación diferentes. El primero buscaba indagar en las transformaciones sociales ocurridas en las dos últimas décadas en la horticultura de Mendoza en dos zonas de producción diferenciadas, el Oasis Norte como zona de producción de "cinturón verde" y el Oasis Centro (más conocido como Valle de Uco), como zona de producción "especializada" (Mundt, 1986, citado en Benencia, 1994) ${ }^{2}$. El segundo trabajo tenía por objeto indagar en los saberes y prácticas que despliegan los horticultores, con énfasis en procesos de transición agroecológica. En ambos trabajos la selección de entrevistas obedeció a un muestreo teórico (Glaser \& Strauss, 1967) e intencionado, que busca una representatividad que responde tanto a criterios geográficos como al tipo de entrevistados. Entre los sujetos relevados se incluyen entrevistados que desempeñan sus labores en empresas capitalistas de diferentes tamaños (18 entrevistas); técnicos de diferentes instituciones (4 entrevistas), y productores campesinos (26 entrevistas), de los cuales 5 realizaban producciones agroecológicas o se hallaban en transición a la misma. En lo sucesivo, los entrevistados serán identificados en el texto, según se trate de asalariados $(\mathrm{T})$ o aparceros (A) que se desempeñan en explotaciones de tipo capitalista, campesinos (C) o campesinos cuyas prácticas agroculturales puedan ser consideradas agroecológicas (CA).

Respecto de las unidades de análisis, en este trabajo nos remitimos específicamente al estudio de explotaciones campesinas a quienes definimos, siguiendo a Bartra (1989), como campesinos modernos. Este 
autor sostiene el carácter estructural del campesino en el capitalismo, apoyado en la no generalización de las relaciones capitalistas en el agro. Por ende, reconoce al ingreso de subsistencia del productor directo que trabaja por cuenta propia como la base de una clase específica dentro del modo de producción capitalista (Bartra, 1989). Esta definición permite además privilegiar las relaciones de producción por sobre las transformaciones técnicas del proceso productivo. Es decir, sostener la definición de campesinos sobre aquellos productores que han sufrido una transformación de la base técnica de su producción, siempre y cuando tales cambios permanezcan dentro de cierto umbral de acumulación acorde al de una familia que dispone de su fuerza de trabajo como principal elemento para capitalizarse (Carballo Hiramatsu, 2019).

Dicho esto, los campesinos entrevistados son sujetos cuyo trabajo se basa, fundamentalmente, en la fuerza de trabajo familiar, con superficies trabajadas que oscilan por lo general entre 1 y 6 hectáreas (ha), con acceso a la tierra, ya sea mediante propiedad, arrendamiento u otra forma, y que además ejercen el control del proceso productivo. Aclaramos esto último debido a que en la horticultura de Mendoza se halla muy extendida una figura llamada "chacarero", nombre con el cual se denomina localmente a una forma particular de aparcería. Bajo esta forma, el aparcero recibe el 30 \% de la producción y solo aporta la fuerza de trabajo. La contraparte, conocida localmente como "patrón", aporta la tierra, insumos y maquinaria; además conserva el poder de decisión sobre el proceso productivo. Consideramos que esta forma ha perdido la condición de una aparcería, ya que ha dejado de vincular partes relativamente simétricas, para convertirse en una relación asalariada encubierta y fuertemente precarizada. Por esto, dichos casos están considerados entre las explotaciones de tipo empresarial y no como campesinos (Carballo e Ivars, 2018).

\section{Una BReve CONTEXTUALIZación históRica de la horticultura en Mendoza}

La provincia de Mendoza (Argentina) se localiza en la llamada "diagonal árida sudamericana", en la latitud de los Andes centrales. El clima predominante es seco: las mediciones anuales de precipitaciones se hallan en valores muy bajos, dado que no superan los 200 milímetros anuales. Al igual que otras zonas secas del oeste argentino, los ríos a partir de los cuales se irrigan sus oasis son de régimen nivopluvial y se alimentan fundamentalmente de la fusión de nieves de la Cordillera de los Andes. 
MAPA 1

Mendoza y sus oasis

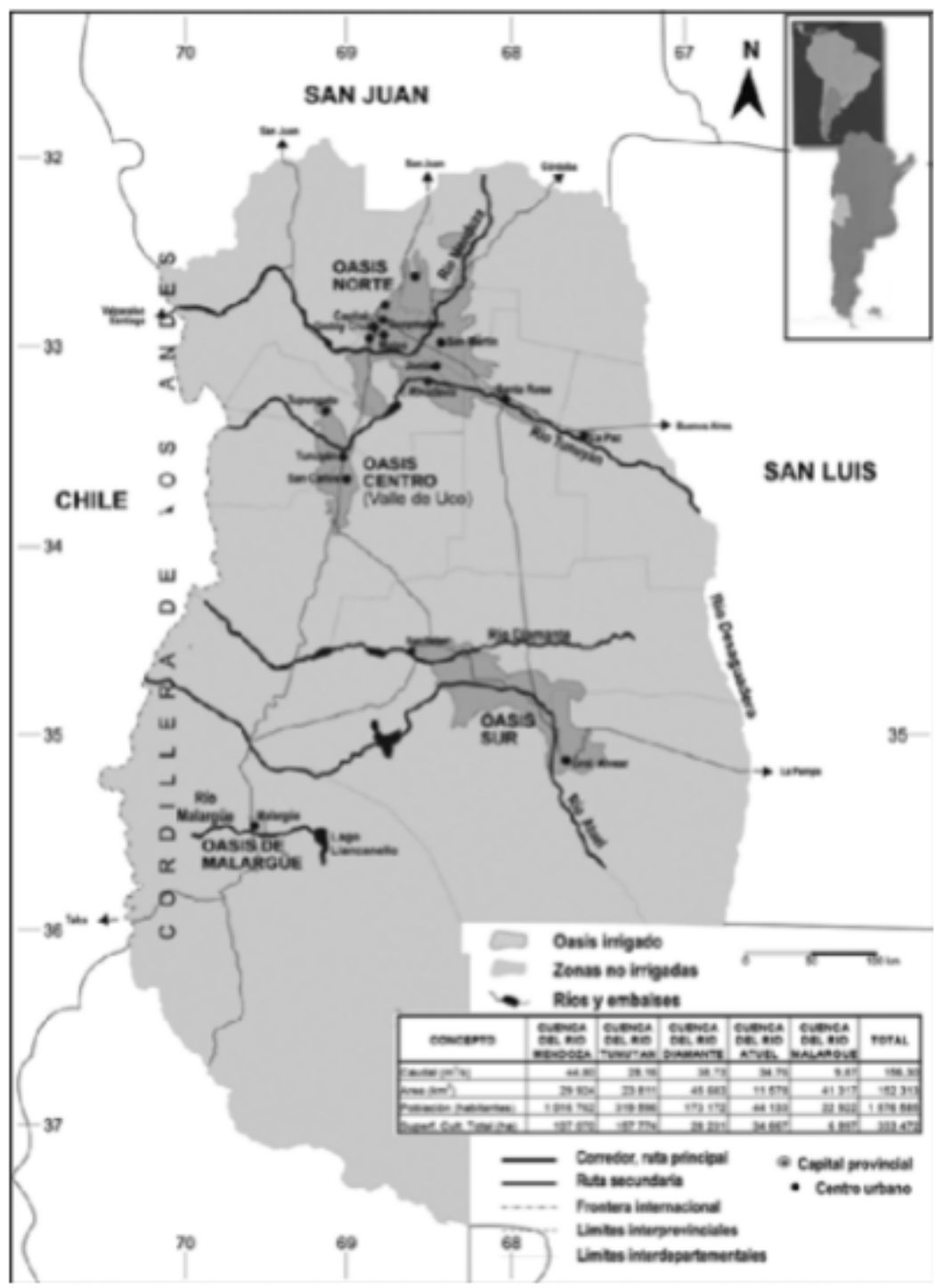

Fuente: Montaña, 2007

Estas condiciones de aridez determinan que la agricultura solo sea posible mediante sistemas de riego artificiales. De este modo, la cuenca de los ríos evidencia un patrón territorial claramente fragmentado (Montaña, 2007); conforma tres oasis irrigados principales y otros menores que apenas ocupan el $5 \%$ de la superficie provincial (Conte, 2013). La producción hortícola representa la tercera actividad agrícola en cuanto a superficie luego del cultivo de vid y frutales. En contraste, el resto de la superficie de la provincia permanece como zonas no irrigadas (planicies y montañas) donde se llevan a cabo actividades extractivas o de cría extensiva de ganado caprino.

La producción comercial de hortalizas en la provincia se remonta a fines del siglo XIX, producto principalmente de los cambios en los patrones alimenticios de la población. El principal cultivo hasta inicios de la década de 1930 fue la papa, seguida por porotos y cebollas. Con el inicio del periodo de sustitución de importaciones, los cultivos hortícolas experimentaron un considerable impulso. Rubio (2001) define la relación del capital con la pequeña producción agropecuaria durante este periodo como un "dominio incluyente". Bajo este modelo, centrado en la valorización del capital en el mercado interno, los campesinos quedaban integrados económicamente -a través de diferentes políticas de protección, fomento y de acceso a 
la tierra-como proveedores de materias primas para las agroindustrias y de alimentos baratos para la creciente población obrera. Durante este periodo los cultivos hortícolas en Mendoza se vieron favorecidos por políticas de promoción y protección arancelaria para las agroindustrias (Rodríguez Vázquez y Barrio, 2018) y por políticas estatales específicas, que tenían como objetivo la adaptación de especies y la producción local de semillas hortícolas (Gallardo, 2012). En este contexto, los cultivos hortícolas doblaron su superficie en el periodo 1930-1940, alcanzando unas 30.000 ha.

Hacia inicios de la década de 1960, el tamaño promedio de las explotaciones hortícolas en la provincia era muy reducido. Según Velasco (1963), el tamaño promedio de las mismas era cercano a las 5 ha, valor que descendía por debajo de las 3 ha en los departamentos más próximos a la ciudad (Furlani, Gutierrez, Butera, De Triolo y Pérez Romagnoli, 1973). La actividad se basaba en el trabajo de familias numerosas, entre las cuales predominaban las de inmigrantes españoles e italianos; era frecuente, además, la contratación de peones al día. Los trabajos de la época coinciden en señalar una mayor difusión de la aparcería en las explotaciones de los departamentos más alejados de la ciudad de Mendoza, lo cual era menos frecuente en sus alrededores (Velasco, Ostuni y Furlani, 1966). La producción dependía de tecnologías tradicionales, tales como el uso de tracción y fertilizantes de origen animal, deshierbe manual y riego por surco o melga.

Con el auge de la "revolución verde", en la década de 1960, comenzaron a tomar fuerza las políticas de "modernización agraria” (Giarracca y Teubal, 2017). Las mismas se proponían "superar el atraso" tecnológico del agro como forma de apuntalar la industrialización del país. Este fenómeno provocó un salto en lo que van der Ploeg (1993) denomina externalización. Es decir, el proceso por el cual el trabajo agrícola se torna crecientemente dependiente de organismos externos, fundamentalmente de bienes provenientes de la industria, pero también de otras unidades productivas agrícolas. Sin embargo, a diferencia de otros países de la región, en Argentina el Estado nacional tuvo una fuerte presencia en el desarrollo y adaptación de las tecnologías de la revolución verde. En el caso que nos toca, es de destacar la actividad de desarrollo genético en cultivos hortícolas llevado a cabo por el Instituto Nacional de Tecnología Agropecuaria (INTA), como así también el trabajo en la producción y distribución de semillas a través de las Asociaciones Cooperadoras de INTA (Gallardo, 2012). Diferente fue el destino de la provisión de fertilizantes y plaguicidas, mercado que dependía casi exclusivamente de la importación por parte de las empresas trasnacionales.

El proceso de adopción tecnológica en la horticultura mendocina fue bastante heterogéneo, de hecho, no podemos hablar de una transformación técnica de carácter masiva sino hasta inicios de la década de 1990. Así, durante la década de 1960 el tractor se extendió ampliamente en las labores de preparación del suelo, en tanto la tracción animal se mantuvo en la mayoría de las tareas de mantenimiento de los cultivos. Algo similar ocurrió con la incorporación de insumos. Desde la década de 1960 ya se utilizaban fertilizantes de base química, sin embargo, la práctica generalizada siguió dependiendo del guano animal complementado con "abonos verdes" 3 y fertilizantes químicos. A partir de la década de 1970 se incorporaron agroquímicos específicos para la horticultura, tales como insecticidas, fungicidas y herbicidas. Su uso también fue acotado, sobre todo respecto de los herbicidas, por lo que el escardillado manual o con tracción animal se mantuvo como el método más utilizado. Uno de los cambios más importantes fue la introducción de semillas híbridas a fines de la década 1980.

El periodo 1976-1989 determinó una etapa de transición para la horticultura en el país (Benencia, 2002). La modernización técnica, el aumento de la productividad y una demanda decreciente, entre otros factores, ocasionaron importantes caídas del número de explotaciones en algunas zonas hortícolas del país (Propersi, 2006; Ringuelet, 2000). Este fenómeno no se repitió en Mendoza, ${ }^{4}$ en parte debido a la reconversión hacia cultivos hortícolas que siguió a la crisis vitivinícola de la década de 1980, como así también al crecimiento del cultivo de ajo para exportación. El cambio más significativo se dio en la organización del trabajo, producto de la creciente incorporación de inmigrantes de origen boliviano bajo la condición de aparceros (Carballo e Ivars, 2018). A su llegada fueron reemplazando progresivamente la mano de obra local. 
Como ya mencionamos, no fue sino hasta la década de 1990 que el fenómeno de externalización en la horticultura mendocina se acentuó abruptamente. Durante esta década la sobrevaluación del peso argentino $^{5}$ y la apertura comercial facilitaron la incorporación masiva de insumos y tecnologías. A partir de allí, el sector experimentó una aceleración de los ritmos de inversión y una fuerte diferenciación social entre productores (Benencia, 2002). Para Rubio (2001), este período constituye una fase agroexportadora neoliberal excluyente que implicó el retiro del Estado de su función reguladora, y el abandono de los mecanismos de apoyo a la pequeña producción. En nuestro país, esta fase trajo consigo la eliminación de casi todos los impuestos a las exportaciones y a la importación de bienes de capital, el desmantelamiento de los organismos reguladores y líneas de crédito estatales para pequeños y medianos productores, etc. (Giarracca y Teubal, 2017). Por su parte, El INTA sufrió una regresión en sus programas de extensión y quedó sometido a mecanismos de competencia por recursos del sector privado como forma de afrontar la reducción presupuestaria (Gallardo, 2012).

Las consecuencias sobre la estructura agraria de este cambio de paradigma fueron profundas. La cantidad de explotaciones con cultivos hortícolas en Mendoza cayó abruptamente. De 6.975 EAP en 1988 se pasó a 5.170 en 2002. La crisis económica del 2001, que precipitó el fin de la convertibilidad, agudizó esta situación, ya que implicó la multiplicación de los costos de los insumos importados en un mercado deprimido y con fuerte desocupación. En medio de la crisis, muchos aparceros lograron convertirse en productores independientes arrendando las tierras que quedaban vacantes. La recuperación económica iniciada en los años siguientes propició un aumento en la demanda, pero sin grandes variaciones respecto a la dependencia de insumos importados. El periodo 2002-2008 volvió a evidenciar una fuerte reducción del número de explotaciones con cultivos hortícolas, con un total de 3.172 EAP en 2008. Todo esto ocurre a pesar de la revitalización del consumo interno y la reactivación de algunas políticas de apoyo a la "agricultura familiar" en el marco de un modelo neodesarrollista (Rofman y García, 2017). Los datos provisorios del censo de 2018 confirman esta tendencia, al contabilizar 2.724 EAP con cultivos hortícolas. ${ }^{6}$ Esta reducción no fue acompañada por una caída de la superficie hortícola, que se mantuvo en torno a unas históricas 30.000 ha, lo que evidencia un fuerte proceso de concentración de la producción. ${ }^{7}$

\section{Particularidades Del PRoceso DE Cientificación EN LOS SABeres De LOS HORTICULTORES}

Como pudimos constatar en el apartado anterior, la horticultura mendocina experimentó un salto en la subsunción real del proceso de trabajo (Marx, 1975) a partir de la década de 1990. El nuevo contexto de apertura económica favoreció la difusión de semillas híbridas y la intensificación en el uso de insumos. Ello introdujo una diferenciación a partir de los rendimientos alcanzados respecto a las prcticas empleadas hasta ese momento. Simultneamente, se consolidó un cambio en los patrones de consumo asociado a la creciente influencia de estándarede calidad que cambiaron la percepción de los consumidores. Aquellos productores incapaces de sostener los crecientes ritmos de inversión vieron reducir sus ingresos frente a una incesante competencia. Impuesta a través del mercado, esta disciplina llevó a una adopción generalizada de los paquetes provistos por las empresas de insumos y semillas.

Con ello, las prácticas culturales y los saberes de los horticultores quedaron subsumidos al proceso de "cientificación" (Ploeg, 1993) proveniente de la dupla ciencia/capital. Este dispositivo de saber-poder (Deleuze, 1999; Foucault, 2007), a partir del cual se configura el conocimiento agrícola dominante, está articulado en torno a grandes empresas que gozan de la legitimidad para sugerir nuevas prácticas y, por tanto, dirigir la conducta de los horticultores en determinada dirección y bajo la lógica de nuevos saberes. No obstante, Landini (2011) sostiene que los campesinos nunca adoptan propuestas técnicas "de manera directa, acrítica o irreflexiva, sino que son evaluadas en cuanto a su utilidad y pertinencia a partir de los 
saberes locales previos y de la propias preferencias y prioridades" (p. 14). Esto significa que la cientificación no puede eliminar la aproximación propia del conocimiento tradicional de los productores directos, es decir, la sabiduría vinculada a la experimentación in situ, las experiencias vitales, el sufrimiento y la vivencia intensa de la cultura (Villoro, 2009).

Estas consideraciones son evidentes en la combinación de saberes de distinta índole, que ponen en práctica los campesinos entrevistados. Como es de esperarse, mucho tienen que ver las trayectorias particulares de los sujetos, más aun si consideramos que la mayoría de ellos son productores de origen boliviano que no hace mucho cultivaban la tierra de una manera completamente diferente. No obstante, es importante destacar que el flujo y direccionalidad de los saberes no es simétrico ni igualitario, sino que la apropiación, uso y manejo de saberes está también sometido a relaciones de fuerza sociales que operan en uno u otro sentido. No obstante, es oportuno recordar el peso de los conocimientos hegemónicos "en tanto el lugar desde el que se produce es el lugar del poder" (Palermo, 2008, p. 3).

Ahora bien, en el estricto plano del análisis cualitativo del material primario, es nuestra intención evidenciar que estos modelos de conocimiento asimétricos no se presentan de forma pura; por el contrario, se trata de observar "los pasos", las "idas y vueltas" de uno a otro. Será pues nuestra tarea en esta controversia analizar en qué momento uno u otro predominan en la práctica agrocultural cotidiana de los horticultores, también desentrañar las disputas que se expresan en la propia experiencia vital de los sujetos que nos prestaron sus testimonios.

En las entrevistas resulta frecuente que los productores describan cierta coexistencia entre la experiencia propia y el conocimiento experto de los ingenieros que los asesoran. Este asesoramiento, cuando se trata de productores pequeños, ocurre principalmente en los locales de venta de insumos y semillas. A lo largo del trabajo en terreno pudimos evidenciar que estos locales comerciales operan como fuentes de conocimiento, y, por tanto, de dirección de las conductas (Foucault, 2007; Mussetta, 2009). Según Mabel, una campesina de El Algarrobal: "vamos a la semillería (...) mi marido ya tiene conocidos, gente que sabe ya de los abonos, del veneno, son todos ingenieros" (C1, comunicación personal, 28 de diciembre de 2012). Ante la pregunta referida a las formas de aprendizaje de las prácticas culturales, Mabel dejó constancia de esta subsunción: "es sabiduría de padre a hijo de muchos años. Se va hasta la semillería o a las personas que tienen sus ingenieros, si tienen algunos productos nuevos te dicen 'mirá para matayuyo, un abono que es mejor que el otro'... Siempre te aconsejan” (C1, comunicación personal, 28 de diciembre de 2012). Otro entrevistado agregó:

Por ahí viene y nos da unas recomendaciones el ingeniero, pero mucho que por ahí no le hacemos caso, porque por ahí son cosas que no tienen sentido. Antes lo probábamos, pero, es lo mismo (...) Lo que es fertilizante y veneno esas cosas, siempre hacemos lo que él dice. En eso sí, porque bueno, uno no sabe mucho de eso (A2, comunicación personal, 29 de diciembre de 2017).

Entre los campesinos entrevistados observamos un grupo que orienta su acción, principalmente, a partir del consejo ingenieril del agrónomo y otro formado por quienes valoran más los saberes propios, aquellos adquiridos a partir de la propia experiencia. Como expresión de esto último, un campesino explica que no tienen "asesor, nosotros plantamos, como siempre plantamos ya sabemos qué tenemos que plantar y qué es lo que da, qué no da, y así nos arreglamos” (C3, comunicación personal, 29 de marzo de 2012). En este sentido, Zulma Palermo (2008) entiende que "la legitimidad del conocimiento se vincula a su localización" (p. 3 ), es decir, que todo conocimiento es local en su origen y se legitima por su capacidad para responder a interrogantes concretos. En esta línea de razonamiento, un entrevistado contrapone la legitimidad y validez del conocimiento abstracto frente al experiencial, cuestionando la pertinencia del primero en el plano concreto:

...yo que estoy, que camino todos los días las plantaciones. Un ingeniero te sabe...ponele, qué químico le viene bien a tal o cual enfermedad o pestes, pero nada más. O sea, el que está acá tiene que saber lo que le falta o le sobra a una planta, ¿̇me entendés? Y vos se los transmitís al ingeniero y el ingeniero bueno, le busca la solución. Pero quien sabe es el que está permanente viendo la producción (A4, comunicación personal, 4 de abril de 2017). 
En el extremo opuesto, el predominio del conocimiento de carácter científico puede alcanzar su cénit cuando se establecen contratos de integración vertical con empresas para la provisión de hortalizas. En tales contextos, las prácticas vinculadas al acervo campesino pueden llegar a desaparecer por completo bajo la supervisión técnica de las mismas. Allí alcanza su máxima expresión la afirmación de Shanin (1976), quien señalaba que en un contexto de creciente dependencia de insumos provistos "cadena arriba" y de demandas específicas "cadena abajo", el trabajador agrícola se asemejaba más a "un obrero especializado en una línea de montaje o a un técnico que a sus antepasados campesinos" (p. 5). Una trabajadora, encargada de un galpón de empaque de una empresa proveedora de hortalizas a supermercados, describió la profundidad que pueden llegar a alcanzar estos controles: "tenemos ingenieros que están todo el tiempo en la finca de ellos (...) se llevan cuadernos de campo, tenemos registro de todo tipo, desde las semillas, el riego hasta lo que se echó. Si se va a curar, se pide una autorización" (T5, comunicación personal, 11 de octubre de 2018).

Las prácticas basadas en saberes ligados a la memoria y a la tradición (Palermo, 2008) y aquellas basadas en el paradigma dominante se imbrican fuertemente, aunque sin dejar de advertir el predominio de estas últimas como un claro indicador del proceso de cientificación (Ploeg, 1993). Esta situación se torna evidente en los casos de inmigrantes bolivianos o del norte argentino de origen campesino que súbitamente pasan de practicar una forma de agricultura de ciclo cerrado a otra fuertemente dependiente de insumos y bienes industriales. En este cambio abrupto muchos de sus saberes quedan circunscriptos a una etapa pasada, o subordinados a las técnicas aprendidas e impuestas por sus patrones. ${ }^{8} \mathrm{Un}$ aparcero jujeño de la zona de Palpalá relató que en su lugar natal vivía "de la hacienda, de las ovejas, las cabras, las gallinas" (A6, comunicación personal, 2 de septiembre de 2016); por lo tanto, a su llegada tuvo que aprender a trabajar en cultivos hortícolas. Sobre este aprendizaje mencionó: "y te van enseñando los patrones un poco, te van explicando qué es lo que hay que hacer” (A6, comunicación personal, 2 de septiembre de 2016). Otro entrevistado, un campesino de origen boliviano, que trabajó en la chacra ${ }^{9}$ en su país hasta los 13 años, recuerda su adaptación al proceso de trabajo que tuvo que afrontar a su llegada a Mendoza. Allí trabajó como aparcero en una gran explotación. Sobre ello comenta: "trabajando y viendo a los otros uno aprende (...) algunos patrones trabajan con ingenieros entonces uno va curioseando" (C7, comunicación personal, 22 de mayo de 2017).

\section{SOlO EL "PAQUETITO", NO HAY ALTERnATIVA}

La cientificación de los saberes es inseparable de la externalización del proceso de trabajo agrícola. A los fines de simplificar, estandarizar, y acelerar los procesos productivos (Bernstein, 2012) la planta pasó a ser concebida como una mercancía producida en serie y el suelo como mero soporte de nutrientes. El proceso de cientificación se retroalimenta no solo a partir de la erosión de las prácticasagroculturales ligadas al conocimiento concreto, sino que también se retroalimenta en la medida en que la incorporación de ciertas tecnologías degrada el complejo equilibrio físico, químico y biológico que se establece entre el suelo y la planta. En estas condiciones el retorno a una situación de equilibrio previa puede llevar un tiempo prudencial que atenta contra el desarrollo de prcticas agroecológicas y facilita la continuidad de la dependencia de insumos industriales.

Como señalamos en el apartado histórico, el proceso de adopción tecnológica en la horticultura local fue bastante heterogéneo. Más allá de las diferencias lógicas que existen según se realice una aproximación por tipo de cultivo o capitalización de los productores, nos interesa establecer ciertas semejanzas o prácticas que se han vuelto un estándar en la producción de hortalizas en Mendoza. A través de ello pretendemos establecer el grado de subsunción de los saberes y prácticas agroculturales como punto de partida de las transiciones agroecológicas que veremos en el apartado siguiente. A partir de nuestro trabajo en terreno, entendemos que existe una sensación, aparente, de falta de alternativas, y una necesidad, inducida, de uso casi obligado de insumos industriales. Un campesino relató: 
Tenés que trabajar así ahora, sí o sí... Sino no podés competir. Por la calidad, no podés vender, el precio. Ponele, una buena mercadería te dice "bueno, vale 20 pesos". Y tenés mala calidad y te dicen: "No, esto vale 10 mangos" ¿Vas a regalarlo, cabrón, si el laburo es de uno? Entonces, por obligación tenés que ir... Yo soy consciente de esas cosas. Pongo menos surcos y lo trabajo bien (...) Si no trabajás con ese sistema, perdés como en la guerra (C8, comunicación personal, 9 de agosto de 2017).

Uno de los cambios más significativos de este fenómeno fue la adopción generalizada de semillas híbridas. Salvo en algunos cultivos como el del ajo, son pocos los cultivos en los cuales aún perdura la práctica del acopio de semillas propias. Incluso en muchos cultivos resulta habitual la tercerización de la cría del plantín. Con esta práctica se busca garantizar la germinación de las semillas -debido a su costo-y además maximizar el uso del suelo, logrando reducir el tiempo que los cultivos pasan en el mismo.

El deseo del capital por mercantilizar la utilización de semillas se enfrenta a las dificultades que implica controlar la reproducción de organismos vivos. Para ello, las empresas han desarrollado mecanismos tanto de orden técnico como legal. En la producción hortícola este control se logró con la introducción de semillas híbridas. Estas semillas se desarrollan bajo "sistemas de mejoramiento tan controlados, que solo pueden sembrarse una vez. En la segunda generación, las semillas resultantes pueden ser estériles, o tener una gran variabilidad genética" (Bravo, 2017, p. 386). Esta práctica implica tanto dependencia como una transferencia de ingresos del agricultor hacia las empresas. Todo ello sin mencionar el abandono y desaparición de miles de especies en desmedro de unas pocas especies comerciales (Toledo y Barrera Bassols, 2008).

El trabajo cualitativo evidenció una considerable pérdida de saberes tradicionales en este aspecto. Varios entrevistados mencionan experiencias de reutilización de semillas híbridas con resultados negativos. Un campesino relató: "parece que lo hacen para hacer una sola cosecha, no es como antes... Una vez plantamos tomate acá, al año siguiente volvimos a plantar y salió muy finito, largo, medio degenerado” (C9, comunicación personal, 1 de septiembre de 2017). De forma similar, otra entrevistada mencionó: "mi vecino una vez sacó semillas de zapallo para volver a replantarlo y no, no le dio, sí o sí lo tenés que comprar” (C10, comunicación personal, 16 de mayo de 2017). La misma entrevistada expresa el desconocimiento en torno al proceso de producción de estas semillas, lo que da cuenta de una ruptura entre el proceso productivo y el de conocimiento: "no sé qué es lo que le echan o cómo lo hacen" (C10, comunicación personal, 16 de mayo de 2017). Esto es fundamental porque no hace muchas décadas la producción hortícola dependía en buena medida de la propia selección que realizaban los horticultores, o del hecho de que las semillas eran desarrolladas y provistas por instituciones estatales a precio de fomento (Gallardo, 2012).

Cuando indagamos en las causas del abandono de la práctica de selección de semillas, es común escuchar que no existen otras alternativas. Le preguntamos a Juan Carlos si él no podía producir su propia semilla, su respuesta fue categórica: "no se puede, no sirve. La mayoría ahora te viene híbrida". Luego se explaya in extenso:

La mayoría [de las semillas] vienen para vender. Entonces vos tenés que ir obligado a comprar, no te queda otra. Y el negocio lo tienen ellos. (...) Vos antes, de un zapallo podías sacarle. Lechuga, nunca compré semillas, y ahora tenés que comprarla (...) Vos plantás una semilla de la tuya, por más buena que sea, y plantás una híbrida, y se da mejor aquella, la que viene en lata. Una calidad espectacular, nada que ver. El color, el tamaño, nada que ver con lo otro, también, súper rendimiento (C8, comunicación personal, 9 de agosto de 2017).

Esta diferencia no es casual, dado que la investigación y desarrollo de esas semillas depende de empresas privadas que privilegian variedades híbridas; de este modo se pueden garantizar un mercado cautivo de material genético (Bravo, 2017). Paralelamente a ello, se abandonaron o quedaron rezagados los desarrollos de semillas de polinización abierta, papel que anteriormente tenía al INTA como uno de los principales protagonistas. Del mismo modo, las asociaciones cooperadoras de INTA quedaron reducidas a un rol testimonial, luego de haber ocupado un lugar de suma importancia en la multiplicación y distribución de semilla hortícola (Gallardo, 2012). Los fragmentos de material primario relevados muestran la pérdida de diversidad que se produce a largo plazo por no operar con semillas de polinización abierta y 
fundamentalmente muestra la extinción de valiosos saberes y experiencias biológicas y culturales que "implica la erosión del acto de descubrir y la reducción de la creatividad” (Toledo y Barrera-Bassols, 2014, p. 190).

En cuanto a las prácticas destinadas a asegurar la fertilidad del suelo o las labores culturales de mantenimiento de los cultivos, encontramos mayor heterogeneidad, aunque todas subsumidas a la lógica de la agricultura industrial. Es en las prácticas para asegurar la fertilidad del suelo donde se observa mayor coexistencia de prácticas tradicionales y de la petroagricultura. Entre los campesinos entrevistados resulta generalizado el uso de guano, combinado en ocasiones con fertilizantes químicos. Incluso algunos destacan la bondad del primero frente a los fertilizantes químicos: "con guano es lo mejor que hay, sirve para una cosecha que es de este año y para una segunda cosecha (...), es mejor, es más factible, más seguro, no es como el abono [químico], el abono es como un fogonazo nomás" (C11, comunicación personal, 2 de junio de 2017). Además, resulta habitual la práctica de la rotación e incluso el descanso del suelo cada cierta cantidad de años. Esto último, sobre todo, cuando se cultivan hortalizas pesadas o de raíz, ${ }^{10}$ que agotan rápidamente el suelo. Sobre esta práctica una entrevistada comentó:

Vos te das cuenta, si vos ves de acá a 5 años que, ponele, no te da la misma cantidad que el año pasado, ahí vos sabes que no tenés que plantarlo más. Tenés que volverle a hacer otro tipo de trabajo, prepararlo, ararlo, regarlo, echarle avena, guano, y eso nada más. En un año se recupera. Si vos le echas guano y le plantas avena y lo tratas como tiene que ser y le echás abono y todas esas cosas (C10, comunicación personal, 16 de mayo de 2017).

En cuanto a las prácticas de mantenimiento de cultivos, también se observa una heterogeneidad de técnicas. Para la eliminación de especies vegetales competidoras, la práctica generalizada es el deshierbe manual o con tracción animal. La difusión del uso de herbicidas es algo más limitada y se emplea generalmente en caso de una gran proliferación de "yuyos", ${ }^{11}$ por ejemplo, luego de fuertes lluvias. También resulta habitual en caso de grupos domésticos reducidos, debido a su menor capacidad de trabajo. En cambio, para la eliminación de insectos y hongos el uso de insecticidas y fungicidas es generalizado. Un entrevistado resumió la necesidad de insumos con la siguiente frase: "abono y curativo, esa es la principal" (C7, comunicación personal, 22 de mayo de 2017).

Más allá de la combinación de prácticas tradicionales con el uso de insumos industriales, la aplicación de estos últimos degrada considerablemente las propiedades naturales de regeneración de suelo, conocidas como ciclado de nutrientes. Así también, afecta el equilibrio biológico, que actúa como un control natural a la proliferación de plagas. En palabras de un campesino en transición agroecológica: "el suelo no tiene vida" (CA12, comunicación personal, 24 de octubre de 2019). Con ello, la solución más rápida a las condiciones generadas por la misma aplicación de insumos permanece en la órbita, nuevamente, de soluciones provistas por la industria. Estas apreciaciones del entrevistado se condicen con abundante bibliografía científica que aborda la relación entre la sobreutilización de insumos industriales y la pérdida de calidad en el suelo. Solo por citar un ejemplo, Bocero (2002), en su análisis de la horticultura en el sur de la provincia de Buenos Aires, señala que al excesivo uso de insumos industriales se le suman diferentes manejos del suelo que debilitan su fertilidad. Entre ellos menciona el uso intensivo, la escasa rotación y tiempo de descanso del suelo. ${ }^{12}$ Todo ello provoca una disminución de la productividad, la alteración de la vida microbiana, y la afectación en el poder de autodepuración del suelo, entre otros problemas.

Ahora bien, estas prácticas agroculturales se enmarcan en la redefinición de las "relaciones institucionales" (Ploeg, 2010) en la horticultura a partir de la creciente preeminencia de la "semillería” y el asesoramiento ingenieril. Estos últimos actualmente constituyen una parte fundamental del nuevo armazón institucional que media las relaciones al interior del campo. De este modo, intervienen en la dirección y ordenamiento de las conductas, no solo en función de saberes científico-técnicos, sino también en función de una lógica privada mucho más ligada a los intereses de empresas productoras de agroquímicos. 


\section{RUPTURA Y TRANSICIÓN HACIA OTRA ECOLOGÍA (AGRARIA)}

Como vimos anteriormente, el proceso de externalización no fue inocuo en términos de concentración económica. Desde la década de 1990 en adelante se observó una incesante desaparición de explotaciones con cultivos hortícolas sin que ello se tradujera en la disminución de las superficies sembradas. En este fenómeno, el incremento de los insumos en los costos de producción tiene un peso considerable y resulta una preocupación constante para los campesinos. Relatos como el de Lucía se repiten frecuentemente: "nosotros hemos dejado de sembrar así papa, cebolla y todo eso por el abono, el abono que viene tan caro" (C13, comunicación personal, 2 de agosto de 2017). La dependencia de insumos externos, además, torna crítico un mal resultado económico. Juan Carlos explicó la sensación luego de un año de malos precios o de pérdidas por inclemencias climáticas: "te da vuelta. Y... lo único que empezás con menos...o te vas a buscar un préstamo. Porque tenés que comprar semillas, guano, venenos” (C8, comunicación personal, 9 de agosto de 2017).

Frente a la acumulación de tensiones vinculadas a la agricultura convencional y a la acuciante necesidad de alternativas, no fue sino hasta fines del pasado siglo que tibiamente estas últimas comenzaron a vislumbrarse en la producción hortícola de Mendoza. Para ello fue necesaria la difusión de "otra ecología" (Toledo y Barrera-Bassols, 2008), motivada por la creciente acumulación de experiencias de los productores acerca de los límites ecológicos y ambientales que implicaba esta forma de hacer agricultura (Altieri, 2013; Altieri y Toledo, 2010), así como un creciente número de científicos que tomaban nota de estas demarcaciones. De este modo, se revalorizaron las sabidurías previas y las memorias de aquellos que recordaban que "antes todo era diferente". A partir de allí empiezan a ganar tibiamente lugar las sabidurías menos arraigadas en conocimientos científicos abstractos y más basados en "conocimientos directos, empíricos y repetitivos acerca de las cosas (...) en la experiencia concreta y en las creencias compartidas por los individuos acerca del mundo circundante y mantenida, y robustecida mediante testimonios" (Toledo y Barrera-Bassols, 2008, p. 101).

Además, para Altieri y Toledo (2010) lo fundamental es que los campesinos tengan la posibilidad de acceder a la tierra, las semillas, el agua, a los mercados locales, no solo a través de políticas públicas destinadas a este fin, sino a que los propios campesinos puedan desarrollar agroecosistemas cada vez menos dependientes de insumos externos. En este sentido, la agroecología

conlleva la diversificación agrícola intencionalmente dirigida a promover interacciones biológicas y sinergias benéficas entre los componentes del agroecosistema, de tal manera que permitan la regeneración de la fertilidad del suelo y el mantenimiento de la productividad y la protección de los cultivos (Altieri y Toledo, 2010, p. 65).

En las rupturas experimentadas por los campesinos con la "agricultura convencional" inciden numerosos factores, que exceden los motivos económicos. Incluso muchas trayectorias son cuando menos curiosas, ya que conllevan profundas reflexiones sobre el ser mismo como agricultor e incluyen en ocasiones intervenciones tan centrales como azarosas. Una horticultora de Guaymallén (CA14, comunicación personal, 11 de diciembre de 2017) nos explica que, aunque la agricultura convencional es más "ventajosa", "fácil", e incluso implica "menos trabajo", ella inició la transición agroecológica en el medio de "una consecuencia dolorosa" vinculada a la enfermedad y posterior fallecimiento de su marido. La enfermedad quedó en ella estrechamente asociada al contacto con agroquímicos: "mi marido agarraba los polvos, los líquidos, los daba vuelta con la mano; para ellos es lo normal”. A partir de esta situación, ella no quiso "saber nada" con la agricultura basada en insumos químicos. En esta experiencia vital, Dina evidencia una ruptura asociada no al conocimiento o aprehensión de una teoría, sino a la vivencia sufriente e intensa, a partir de la cual adquirió aprendizajes basados en su propia experiencia vital (Villoro, 2009).

En el medio de estos acontecimientos, con su marido gravemente afectado por la enfermedad y 7 hijos pequeños a cargo, se vinculó a otras personas que "pensaban distinto" y le propusieron "producir verdura sin veneno", aprovechando que era propietaria de la tierra y que tenía conocimientos en agricultura: "vos producís, nosotros te ayudamos a vender”. De este modo, ella se incorporó a un sistema de comercialización 
por internet ya consolidado llamado Siembra Diversa. Inicialmente dividió su parcela en partes iguales entre agricultura convencional y agroecológica. Explica que durante esa primera experiencia ella producía mayor cantidad de verdura con los métodos convencionales, sin embargo, luego de costear los gastos, "no le quedaba nada". Por el contrario, "en el reparto hacía el $30 \%$ del laburo que hacía para la feria convencional, y me quedaba plata".

Inicialmente, la conversión agroecológica implicó una intensificación del trabajo en la explotación. En primer lugar, la formación de un equilibrio biológico requiere cierta práctica y tiempo. Ello se logró mediante la rotación de cultivos y la utilización de bioinsumos. "Ya se armó el equilibrio. Ya no hace mucha falta que estés echando tierra diatomea. (...) Si vos abrís un poco ahí el surco vas a ver, tenés arañas, avispitas, gusanitos, hay de todo, acá el control se armó ya...”. En segundo lugar, la reducción de la densidad de especies vegetales competidoras implicó una extensa dedicación al deshierbe manual. "Tenía cantidad de yuyos, no me dejaba ni trabajar, era como un colchón (...) Ahora yo tengo tres clases nada más de yuyo... Y en el invierno me queda uno solo". La fertilidad del suelo se logra mediante guano de caballo y gallinas propias, además de las rotaciones, lo que se suma a toda clase de abonos verdes y biopreparados. Describe que luego de la aplicación de estos últimos: "al otro día ves otro color. Es re loco, de no creerse. Todo se ve diferente. Es como que le da más brillo, más vida” (CA14, comunicación personal, 11 de diciembre de 2017).

Por su parte, Ernesto (CA15) nos cuenta que su trayectoria a una producción agroecológica fue un tanto azarosa. Durante algunos años continuó trabajando de la manera aprendida anteriormente como obrero en una chacra convencional. "Sabía pero me faltaba... viste. Yo me crié haciendo chacra, donde yo estaba plantábamos 200 ha de cebolla, 200 ha de tomate... estaba en una de las fincas más grandes”. En el año 2000 pudo arrendar una parcela. Sobre esos inicios comentó: "cuando empecé, solo venía y plantaba, y me ganaba el monte, me ganaba la maleza". En una oportunidad su producción se vio afectada por una granizada: "hacía una sola cosa, todos estos cuadros con melón, y me agarró una manga de piedra y no me dejó nada”, nos cuenta. Al recorrer las zonas aledañas a su finca, pudo observar un cultivo de alfalfa que permaneció indemne al granizo: "justo fui para allá (...) y al pasto no le había hecho nada". A partir de ese momento comenzó con la siembra de alfalfa y "eso fue algo, que se yo... una bendición". Ernesto trae a la memoria otro hecho, como hilos de continuidad que fortuitamente guardan saberes: "yo tenía un librito muy viejo, era un librito que lo encontré en una casa abandonada, y estuve leyéndolo un poco, y la gente antes hacía eso, esas rotaciones, de alfalfa, vicia, cebada, y después hacía chacra... pero planificaba" (CA15, comunicación personal, 27 de septiembre de 2019).

Con la siembra de alfalfa, Ernesto solucionó uno de sus principales problemas: “acá había una maleza impresionante, yo cuando planté los primeros años era imposible, tenía que echar RoundUp, ponerle los tarros y se venía el monte. El clavelillo, era impresionante, se chupa todo". Con la siembra de la alfalfa las hierbas sencillamente se desvanecieron, "lo fulminó, el pasto [la alfalfa] no dejó nada, el clavelillo desapareció". Ernesto comenzó a rotar las tierras con alfalfa y cultivos hortícolas aprovechando el aporte de nutrientes al suelo, "la alfalfa le deja mucho nitrógeno a la tierra, queda linda, no tenés que gastar en abono, nada". Luego de un ciclo de unos 4 o 5 años con alfalfa la tierra puede destinarse a cultivos hortícolas. "No echo nada, ya después hago chacra, pegarle una curadita [con azufre] nomás (...) pero abono nada, porque ya el suelo tiene mucho nutriente (...) hasta tres años podés hacer chacra, sin echarle... capaz que algún guano como para ayudarle, pero casi nada”. Además, en los últimos años, Ernesto ha incorporado el pastoreo de animales en los potreros. Siguiendo con su relato:

cuando termina la temporada, y veo que queda un corte de alfalfa, entonces le echo los animales y está todo enguanado ahí. Muchos decían “'ipara qué metiste los animales? ite van a romper todo!”, y yo por ahí dudaba, pero después se viene mucho mejor (CA15, comunicación personal, 27 de septiembre de 2019).

Esta serie de hechos encadenados le permitieron abandonar casi por completo el uso de herbicidas, a la vez que fertilizar el suelo. Esta experiencia refrenda que "el manejo del suelo y de la agrobiodiversidad cultivada y 
espontánea puede determinar la obtención de los servicios de regulación que redunden en beneficios directos para los agricultores, favoreciendo el camino hacia sistemas de producción agroecológicos" (Pérez y Marasas, 2013, p. 37).

El acercamiento y posterior transición agroecológica iniciada por Jorge (CA16) posee una aproximación quizá más filosófica. Hasta sus 30 años Jorge no tenía vínculo alguno con la agricultura ni con el campo, aunque sí tenía clara su atracción por la naturaleza. Mientras cursaba estudios en Buenos Aires conoció a Rolando, quien luego de cierto tiempo le ofreció trabajar en una finca en Mendoza. Esta finca, una antigua propiedad vitivinícola que supo tener 140 ha en producción, estaba en un proceso de recuperación luego de permanecer improductiva durante varios años. Junto a las plantaciones de vid y olivos existentes comenzaron a realizar cultivos hortícolas como pimiento, tomate y cebolla. Allí Jorge aprendió el oficio y se convirtió en encargado de la finca.

La crisis argentina del 2001 fue un punto de inflexión. "Ellos habían dejado de invertir, y yo estaba desesperado, teníamos la luz cortada, el agua cortada, hacíamos cualquier cosa para tratar de mantenernos". Esta coyuntura puso en marcha una serie de factores que llevaron a Jorge a incursionar en la producción orgánica. En ese momento, Jorge sumaba ya muchas lecturas sobre antroposofía y agricultura biodinámica por cuestiones de salud. "Yo me di cuenta que era el momento del cambio". A ello se sumó que en la finca ya se usaban pocos agroquímicos. "Se usaba muy poco por una cuestión... primero porque la finca estaba en recuperación cuando la agarré, después porque no había plata, y después porque no hacía falta" (CA16, comunicación personal, 18 de octubre de 2019).

En estos primeros años, Jorge pasó de hacer monocultivos a comprender la necesidad de combinar cultivos y fomentar un ambiente biodiverso. Sobre ello menciona:

...logrando la biodiversidad vos lográs que la naturaleza o el universo conspire para que todo salga bien. (...) Si nosotros hacemos una agricultura con biodiversidad desde el vamos, la naturaleza es menos agresiva con nosotros. Si yo hago las cosas que puedo hacer en este suelo, con este suelo, tengo un poco menos de complicaciones (CA16, comunicación personal, 18 de octubre de 2019).

Es decir, la biodiversidad implica para él un equilibrio con el medio, y que las modificaciones en este sentido llevan su tiempo:

La tierra se puede mejorar a nivel agrícola. La manera energéticamente más suave y más sencilla es generando vida (...) de acuerdo a ese suelo tratar de desarrollar las especies vegetales y animales que se puedan desarrollar, mejorando cada vez más las condiciones y esa producción vegetal y animal va a ir dando estructura nueva al suelo (CA16, comunicación personal, 18 de octubre de 2019).

La transición de Juan (CA12) como productor agroecológico es mucho más reciente. Juan llegó al país, procedente de Bolivia, hace unos 25 años aproximadamente. Su experiencia en las labores agrícolas se construyó a lo largo de toda su vida y bajo las más variadas concepciones. Juan nació en una familia campesina en Bolivia, en su juventud trabajó en el norte de su país y en Salta para algunas empresas agrícolas. Hace nueve años llegó a Mendoza, donde trabajó como cosechador. Con su esfuerzo logró adquirir un camión e incursionó como cuadrillero. Sin embargo, no duró mucho en este oficio, ya que no le gustaba "reclamarle a la cuadrilla" las directrices de los empleadores. Aprovechando el camión, comenzó comprar hortalizas y a comercializarlas en un puesto alquilado en una feria. Finalmente, hace dos años se volcó a la producción directa arrendando una finca en el departamento de Guaymallén. En parte su decisión se basó en la observación del suelo, que reviste para él un claro motivo de satisfacción. Esta zona de Guaymallén constituyó no hace más de 150 años un sistema de pantanos, por lo cual posee suelos muy ricos en materia orgánica, además de ser una zona de surgencia de agua subterránea. Allí decidió directamente producir sin insumos, siguiendo los aprendizajes que aún conserva de su familia en Bolivia, con la cual guarda fluidos intercambios de saberes y prácticas. Sin embargo, Juan señala las dificultades que conlleva una transición en un suelo que ha sido trabajado muchos años en forma "convencional", es decir, con la aplicación de 
agroquímicos. En sus propias palabras, ese suelo "no tiene vida" (CA12, comunicación personal, 24 de octubre de 2019). En relación a esta apreciación del productor, algunos estudios vinculados a la horticultura (Cuellas et al. , 2017; Cuellas, 2006) demuestran que la "hiperfertilización" en las actividades hortícolas afecta la materia orgánica (MO) del suelo, dado que disminuye su fertilidad y calidad. Actualmente Juan se hallaba abocado a la recuperación de la fertilidad a partir de la aplicación de bioinsumos y una rotación con cultivos que aportan nutrientes al suelo, aunque estaba evaluando la posibilidad de tener que incorporar algún fertilizante químico temporariamente.

Visto de este modo, la transición implica el despliegue y desarrollo de un conjunto de prácticas de "reproducción autónoma" (Ploeg, 1993, p. 173). Es decir, la creación de una base de recursos para la reproducción de ciclos futuros con el objetivo de reducir la dependencia de insumos provenientes del mercado. Si seguimos a van der Ploeg, "lo específico del campesinado es que la autonomía y el progreso se crean a través de la coproducción del ser humano y la naturaleza viva” (Ploeg, 2010, p. 37). De esta manera, a medida que se refuerza la autonomía mejoran las expectativas de futuro en la interacción con el mercado.

\section{Procesos colectivos como condición PARA UnA PRODUcción AGROBIODiversa}

Existe una compleja relación entre los cuestionamientos que los propios productores hacen de su práctica y la presencia activa de organizaciones que promueven la agroecología. Una vez que los productores incorporan prácticas agroecológicas, la participación en organizaciones y colectivos refuerzan no solo las transiciones, sino también la persistencia en este tipo de agricultura, sobre todo en las primeras etapas, que son las más complejas. Al respecto, Pablo Tittonell (2019) sistematiza el proceso de transición hacia la agroecología como una secuencia específica de fases: predesarrollo, despegue, irrupción y estabilización. Las primeras fases -la transición propiamente dicha-, es decir, el despegue e irrupción, "aparecen favorecidas por la actividad de los movimientos y las organizaciones sociales, incluyendo a productores y consumidores, y por un apoyo creciente a partir de los organismos del estado". Esto sin perjuicio de que muchos productores, "aun sin saberlo, pueden exhibir grados avanzados de adopción de prácticas agroecológicas” (Tittonell, 2019, p. 243)

En el caso de Dina, y como explicamos anteriormente, fue precisamente una compañera de estudio quien le propuso producir verduras agroecológicas para un reparto domiciliario. A medida que se consolidaba en este circuito de comercialización, fue convocada a Bioferia Mendoza como proveedora de hortalizas en ese espacio “y empezamos a tener más y más clientes (...) Ahí yo hacía a full, trabajamos toda la hectárea y te digo que... de repente hay muchos que quieren verdura orgánica y tengo que decirles que no, porque ya estamos saturados" (CA14, comunicación personal, 11 de diciembre de 2017). Por su parte, Ernesto apeló a vínculos que fue construyendo de modo personal en un mercado concentrador local: "me hice amigo de unos muchachos; al principio me costó y ya ellos me hacían entrar, iba y descargaba nomás, y ellos vendían, llevaba buena mercadería, y se vendía”. Mediante el cultivo de vínculos personales, a través de la confianza en la calidad de su producción, también consiguió que un comerciante le comprara 1.000 botellas de salsa cada año: "si vos vas y decís, la fruta la hago yo y la hago casi orgánica, y vos le conversás, y la gente se da cuenta y te empieza a comprar” (CA15, comunicación personal, 27 de septiembre de 2019).

Otros aspectos en los que se sinergiza la acción entre las organizaciones y las prácticas agroecológicas es en lo que denominamos intercambios materiales y simbólicos, ya sea material genético como semillas, o experiencias y conocimientos. Dina relata que se siente a gusto en las ferias, "esas semillas las traje el año pasado de Chile (...) he ido a Uruguay a ferias de semillas (...) seguimos juntando semillas de tomate y así sucesivamente (...) vamos haciendo un reservorio de semillas que en el mercado no hay" (CA14, comunicación personal, 11 de diciembre de 2017). De hecho, estos intercambios pueden darse cuando existen relaciones fluidas y de amistad entre los productores. Al respecto, Ernesto comentó que siempre está a la búsqueda de nuevas semillas: "yo voy buscando semillas que no son tan híbridas, voy guardando, porque esa es la idea de ir guardando”. Esta búsqueda la realiza principalmente en el medio local observando 
e intercambiando ideas con productores de la zona: "yo siempre le pido a alguno que haya plantado, tengo unos muchachos amigos paisanos [bolivianos] (...) Y siempre nos juntamos a comentar algo" (CA15, comunicación personal, 27 de septiembre de 2019).

De estos intercambios, Ernesto ha ido recuperando diversos saberes técnicos surgidos de la experimentación: "yo he ido aprendiendo, hay que gente que dice 'cortás la parte de atrás del melón, o del zapallo, y eso lo tirás, y sacás de la parte del tronco, eso es lo que sale todo parejito'. Eso se aprende charlando" (CA15, comunicación personal, 27 de septiembre de 2019). Sin tales intercambios seguramente estos saberes no trascenderían más allá de sus descubridores. Otro productor mencionó una práctica colectiva tendiente mejorar la genética de los cultivos. Santos aprendió esta práctica en su lugar natal, Ledesma, en la provincia de Jujuy: "vos traés papa de Bolivia o maíz y cambian, y llevan para allá, para Bolivia y así le hacen, y vienen a cambiar semillas, a traer la semilla de ellos y llevan otra semilla para allá". Don Santos estaba comenzando a aplicar localmente estos intercambios: "la semilla cambiarla como ser de San Carlos [Valle de Uco] a aquí” (CA17, comunicación personal, 13 de febrero de 2020).

El papel de las organizaciones también resulta un lugar privilegiado para el desarrollo de los procesos de transición agroecológica; allí los agricultores intercambian conocimientos entre ellos y con los técnicos que forman parte de las mismas. En este sentido, Ernesto (CA15) recupera las capacitaciones en el uso de bioinsumos realizados en la UST (Unión de Trabajadores Rurales Sin Tierra) de la cual es parte, y señala la necesidad de un banco de semillas: "eso para el día de mañana va ser importante". Juan (CA12) forma parte de la misma organización y recientemente se ha incorporado a los intercambios técnicos, en los que toman parte también agricultores y técnicos de otras organizaciones sociales. De un modo similar, Jorge menciona la importancia que tuvieron en su práctica agrocultural cotidiana las reuniones que realizaban en distintas provincias de la Asociación para la Agricultura Biológico-dinámica de Argentina (AABDA). Jorge recuerda: "en ese momento había viejos productores que habían inmigrado de Europa y traían las ideas de Steiner, y ellos las utilizaban en sus propiedades rurales". Dina recientemente se ha incorporado a las capacitaciones que realiza $A A B D A$ y participa de manera muy activa de encuentros latinoamericanos de este tipo de agricultura.

\section{Conclusiones}

En el presente trabajo intentamos dar cuenta de una problemática muy poco analizada en las tierras secas del oeste argentino. En primer lugar, nos propusimos evidenciar la correspondencia entre la naturaleza de los saberes de los horticultores del Oasis Norte y Centro de Mendoza y sus prácticas agroculturales asociadas, con especial énfasis en cómo se crean, aceptan e imponen los mismos. En segundo término, nos propusimos analizar los procesos de ruptura de prácticas y saberes hacia una transición agroecológica, sus condiciones de posibilidad, y, también, su naturaleza contingente.

Como se pudo observar en el trabajo, los datos censales analizados evidencian un proceso sostenido de pérdida de explotaciones y de concentración de la producción. Entendemos que la creciente dependencia de insumos, las sucesivas reconfiguraciones socioeconómicas acaecidas en el marco de la internacionalización de la agricultura, y la intensificación del proceso de cientificación propiciaron que las prácticas agroecológicas irrumpan como alternativa. Esto, sin perjuicio de que uno de los primeros elementos que pudimos poner en evidencia es el hecho de que los estándares productivistas ligados a la revolución verde constituyen el elemento dominante del acervo de saberes de los productores. Partimos del supuesto de que el vínculo cienciacapital, como una dupla de saber-poder (Foucault, 2007) dominante, incentivó diversas formas y grados de aceptación de estos conocimientos por parte de los campesinos. No obstante, los fenómenos de ruptura reseñados expresan una síntesis de saberes concretos y abstractos (Toledo y Barrera Bassols, 2008), es decir, conocimiento experiencial y científico.

Ahora bien, resultó patente que las transiciones agroecológicas no son procesos lineales ni fáciles de enfrentar por parte de los productores. Tanto la práctica agrocultural como los agroecosistemas presentan 
una inercia que no es tan fácil de romper. Como pudimos ver, los productores reconocen algún alivio en el pesado trabajo agrícola que implica utilizar semillas híbridas, herbicidas, plaguicidas y fertilizantes de síntesis química. Al mismo tiempo, el suelo desprovisto de gran parte de su biodiversidad también necesita un tiempo, no precisamente comercial, para renovar sus procesos, y, generosamente, entregar su plenitud al trabajo del horticultor. Frente a esta realidad, algunos productores iniciaron transiciones agroecológicas a partir de trayectorias disímiles, contradictorias e, incluso, azarosas.

Las experiencias de transición agroecológica que aquí pusimos de relieve nos muestran que, para llevarlas a cabo, requieren precisamente del despliegue de prácticas de "reproducción autónoma" (Ploeg, 1993), de modo tal que puedan constituir una base de recursos que refuerce las sinergias entre el trabajo humano y la naturaleza viva, en un proceso de coproducción más armonioso con el entorno, mientras se tiende a una producción menos tóxica para los consumidores y los propios trabajadores.

La experiencia colectiva tiene suma importancia, ya que la práctica agroecológica se desliga de la estandarización que implica la agricultura industrial, y recupera la heterogeneidad y variación propia de la vida en cada lugar. Para ello no hay recetas armadas; una de las principales formas de desarrollar esta simbiosis radica en recuperar la experimentación y la diversidad biológica y práctica. En este juego, el intercambio de experiencias, angustias, incertidumbres y alegrías resulta central. Podemos advertir que los productores colectivamente organizados logran sustraerse de las "relaciones de fuerza establecidas como saberes constituidos" (Deleuze, 1999, p. 157), y, de ese modo, no solo pueden expresar fugas apenas perceptibles, sino también encarnar una alternativa a la dupla saber-poder dominante. Las condiciones para que estas experiencias prosperen siempre se dan en paralelo a construcciones colectivas por las cuales circulan, se propagan y resignifican tanto los conocimientos como los medios necesarios para la producción y sus productos.

En este contexto, se presentan formas de habitar que huyen de los agrotóxicos; se escapan por entre las grietas del suelo, y desde un lugar inhóspito se impulsan con propuestas germinales, insospechadas y azarosas. Esta episteme, que se rastrea en los pasos ancestrales, se representa en señales curiosas e inciertas que encontramos en registros mínimos de un cuaderno, un pequeño libro prerrevolución verde, en relatos orales y en un conocimiento transmitido en la práctica cotidiana de ponerle el cuerpo, de meter las manos en la tierra.

\section{ReFerencias Bibliográficas}

Altieri, M. A. (2013). La agroecología frente a la crisis alimentaria global. Letras Verdes. Revista Latinoamericana de Estudios Socioambientales, 4, 3-4. Recuperado de: http://repositorio.flacsoandes.edu.ec/handle/10469/876

Altieri, M. A., y Toledo, V. M. (2010). La revolución agroecológica de América Latina: Rescatar la naturaleza, asegurar la soberanía alimentaria y empoderar al campesino. Instituto Latinoamericano para una Sociedad y un Derecho Alternativos (ILSA), 42, 163-202.

Bartra, A. (1989). Campesinado. Base económica y carácter de clase. Cuadernos de antropología social, 3, 3-10. https: //doi.org/10.34096/cas.i3.4847

Benencia, R. (1994). La horticultura bonaerense: lógicas productivas y cambios en el mercado de trabajo. Desarrollo económico 34(133), 53-73.

Benencia, R. (2002). Transformaciones en la horticultura periurbana bonaerense en los últimos cincuenta años. El papel de la tecnología y la mano de obra. Actas del XIII Congreso de la Asociación Internacional de Historia Económica, Buenos Aires.

Bernstein, H. (2012). Dinámicas de clase y transformación agraria. México: Porruá

Bocero, S. (2002). Cultivos protegidos y problemas ambientales: un estudio de la horticultura marplatense en la década del noventa (Tesis de maestría inédita). FLACSO, Buenos Aires. 
Bravo, E. (2017). La concentración corporativa en la industria de semillas hortícolas. En H. Alimonda, C. Pérez, y F. M. García (coord.), Ecología política latinoamericana. Vol. II (pp. 385-401). Ciudad Autónoma de Buenos Aires: CLACSO.

Carballo Hiramatsu, O. A. (2019). Concentración y resistencias en la producción hortícola del Oasis Norte y Centro de Mendoza. Argentina. (Tesis doctoral inédita). Universidad Nacional de Córdoba, Córdoba.

Carballo Hiramatsu, O. A., e Ivars, J. D. (2018). Subsunción formal de formas de organización de trabajo recíprocas: El caso de las "turnas" en la horticultura de Mendoza en Argentin. Boletin Cientifico Sapiens Research, 1(8), 71-83.

Conte, S. (2 de septiembre de 2013). El oasis productivo de Mendoza creció a 4,8 \% del territorio. Los Andes. https:/ /www.losandes.com.ar/oasis-productivo-mendoza-crecio-48-territorio-735747/

Cuellas, M. (2006). Control de salinización del suelo mediante sistemas de drenes en producciones intensivas de cultivos bajo cubierta (Tesis de maestría inédita). Universidad de Buenos Aires. Buenos Aires.

Cuellas, M., Delprino, M. R., D'Angelcola, M. E., Valenzuela, O., Czepulis Cáseres, J., Del Pardo, C., Ciaponi, M., y Mitidieri, M. (noviembre, 2017). Evaluación de la calidad de los suelos horticolas periurbanos mediante el uso de indicadores. Buenos Aires: INTA. Recuperado de https://inta.gob.ar/documentos/evaluacion-de-la-calidad-de -los-suelos-horticolas-periurbanos-mediante-el-uso-de-indicadores

Deleuze, G. (1999). ¿Qué es un dispositivo?. En Michel Foucault, filósofo (pp. 155-163). Editorial Gedisa.

Foucault, M. (2007). Nacimiento de la biopolitica: Curso en el College de France (1978-1979) (Vol. 1). Buenos Aires: Fondo de Cultura Económica.

Furlani de Civit, M. E. F., De Manchon, M. J. G., Butera, M. R., De Triolo, S. L., y Pérez Romagnolli, E. E. (1973). La Competencia por el Suelo Guaymallén-Mendoza. Revista Geográfica, 78, 55-101

Gallardo, G. S. (2012). Desarrollo institucional y politica cientifica: El caso de la producción nacional de semilla hortícola (Tesis de maestría inédita). Universidad Nacional de General Sarmiento, Buenos Aires.

Glaser, B., \& Strauss, A. (1967). The Discovery of Grounded Theory: Strategies for Qualitative Research. Chicago: Aldine

Giarracca, N., y Teubal, M. (2017). Del desarrollo agroindustrial a la expansión del "agronegocio": El caso argentino. En M. Teubal (Ed.), Estudios rurales y movimientos sociales: Miradas desde el Sur. Antología esencial (pp. 349-379). Ciudad Autónoma de Buenos Aires: CLACSO.

Instituto Nacional de Estadísticas y Censos INDEC (2009) Censo Nacional Agropecuario 2008 - Resultados anticipados. Recuperado de https://www.indec.gob.ar/ftp/cuadros/publicaciones/cna08_08_09.pdf

Kvale, S. (1996). InterViews: An introduction to qualitative research interviewing (Nachdr.). Thousand Oaks, CA: Sage.

Landini, F. P. (2011). Racionalidad económica campesina. Mundo Agrario, 12(23), 1-27.

Lastra, S., y Perales Rivera, H. (2007). Producción campesina con alto uso de insumos industriales: el cultivo de repollo (brassica oleracea var. capitata) en los altos de Chiapas. Ra Ximhai, 2(3), 481-507.

Marx, K. (1975). El capital: Crítica de la economía politica. Tomo 1 (Vol. 2). Buenos Aires: Siglo XXI.

Mandel, E. (1995). Long waves of capitalist development: A Marxist interpretation: based on the Marshall lectures given at the University of Cambridge (2nd rev. ed). Londres: Verso.

Montaña, E. (2007). Identidad regional y construcción del territorio en Mendoza (Argentina): memorias y olvidos estratégicos. Bulletin de l'Institut français d'études andines, 36(2), 277-297. https://doi.org/10.4000/bifea.3908.

Mussetta, Paula. (2009). Foucault y los anglofoucaultianos: una reseña del Estado y la gubernamentalidad. Revista mexicana de ciencias politicas y sociales, 51(205), 37-55. http://dx.doi.org/10.22201/fcpys.2448492xe.2009.20 5.41086

Palermo, Z. (2008). Revisando fragmentos del «archivo» conceptual latinoamericano a fines del siglo XXI. Tabula Rasa, 9, 217-246. Recuperado de: https://www.redalyc.org/articulo.oa?id=396/39600912

Pérez, M., y Marasas, M. E. (2013). Servicios de regulación y prácticas de manejo: Aportes para una horticultura de base agroecológica. Revista Ecosistemas, 22(1), 36-43. https://doi.org/10.7818/re.2014.22-1.00

Ploeg, J. D. van der. (1993). El proceso de trabajo agrícola y la mercantilización. En E. Sevilla Guzmán y M. González de Molina (Eds.), Ecologia, campesinado e historia (pp. 153-195). Madrid: Ediciones de La Piqueta.

Ploeg, J. D. van der. (2010). Nuevos campesinos: Campesinos e imperiosalimentarios. Barcelona: Icaria. 
Propersi, P. (2006). Persistencia y cambio de las unidades de producción hortícola en el Cinturón Verde del Gran Rosario. Mundo Agrario, 7(13). Recuperado de https://www.mundoagrario.unlp.edu.ar/article/view/v07n13 $\underline{\mathrm{a} 02 / 1168}$

Ringuelet, R. (2000). Introducción: El Sector Hortícola de La Plata en proceso de transformación. En R. Ringuelet (comp.), Espacio tecnológico, población y reproducción social en el sector horticola de La Plata. (pp. 13-21). Buenos Aires: UNLP FAHC.

Rodríguez Vázquez, F., y Barrio, P. (2018). Diversificación agroproductiva en Mendoza, Argentina. El tomate fresco y procesado en la década de 1930. Región y sociedad, 30(73). https://doi.org/10.22198/rys.2018.73.a1001

Rofman, A., y García, I. (2017). Economías regionales en el contexto del proyecto neoliberal en marcha. Realidad Económica, 310, 47-86.

Rubio, B. (2001). Explotadosy Excluidos. Los campesinos latinoamericanos en la fase agroexportadora neoliberal. México: Plaza y Valdéz

Shanin, T. (1976). Naturaleza y lógica de la economia campesina. Barcelona: Anagrama.

Stake, R. (1995). The Art of Case Study Research. Thousand Oaks, CA: Sage.

Taylor, S. J., y Bogdan, R. (1992). Introducción a los métodos cualitativos de investigación: La búsqueda de significados. Barcelona: Paidós.

Tittonell, P. (2019). Las transiciones agroecológicas: Múltiples escalas, niveles y desafíos. Revista de la Facultad de Ciencias Agrarias. Universidad Nacional de Cuyo, 51(1), 231-246.

Toledo, V. M., y Barrera Bassols, N. (2008). La memoria biocultural: La importancia ecológica de las sabidurias tradicionales. Barcelona: Icaria Editorial.

Vasilachis de Gialdino, I. (Ed.). (2006). Estrategias de investigación cualitativa (1. ed). Buenos Aires: Editorial Gedisa.

Velasco, M. (1963). La horticultura en Mendoza. La técnica agrícola, la estructura agraria y el valor económico de las hortalizas. Boletín de Estudios Geográficos, X(39), 41-89.

Velasco, M., Ostuni, J., y Furlani, M. (1966). Estudio de geografía agraria de Carrizal y Ugarteche. Boletín de Estudios Geográficos, XIII(50), 1-96.

Villoro, L. (2009). Creer, saber, conocer. México: Siglo XXI Editores.

Walker, R. (2004). The conquest of bread: 150 years of agribusiness in California. New York: The New Press.

Yin, R. K. (1994). Case study research: Design and methods (2. edition). Thousand Oaks, CA: Sage.

\section{Notas}

1 "Los resultados de la ciencia se transmiten mediante discursos, consignados en tratados, artículos, manuales; las verdades de la sabiduría pueden comunicarse aún sin palabras, mediante el ejemplo de una vida. La sabiduría se atribuye con mayor facilidad a los hombres viejos, experimentados o bien a los que han sobrevivido a múltiples experiencias vitales y han sabido sobrevivir a ellas; pensamos que es más sabio el que ha sufrido y vivido intensamente y ha podido guardar las enseñanzas de situaciones variadas en las que ha participado" (Villoro, 2009, p. 226).

2 Según esta clasificación los cinturones verdes se ubican en torno a las ciudades y producen una amplia variedad de verduras de hoja y hortalizas de estación. En tanto las zonas hortícolas especializadas y áreas de horticultura extensiva se hallan por lo general lejos de las principales ciudades y producen unos pocos cultivos. Las áreas de horticultura extensiva se caracterizan además por la siembra en grandes áreas y cierta mecanización (Mundt, 1986, citado en Benencia, 1994).

3 Materia orgánica producto de siembras anteriores.

4 El Registro Permanente de Uso de la Tierra (RUT) de la Provincia de Mendoza registró 5.448 explotaciones con cultivos hortícolas en el año 1971; en tanto el Censo Nacional Agropecuario de 1988 daba cuenta de 6.975 EAP de este tipo. Si bien estas fuentes no resultan comparables debido al carácter no exhaustivo del RUT, podemos afirmar que en Mendoza no ocurrió el drástico descenso de explotaciones registrado en los mencionados estudios sobre la región pampeana.

5 La llamada Ley de Convertibilidad, que rigió entre marzo de 1991 y enero de 2002, establecía la paridad cambiaria 1 a 1 entre el peso argentino y el dólar estadounidense.

6 Datos provenientes del Censo Nacional Agropecuario (CNA) 1988, 2002, 2008 y 2018. Como resulta de público conocimiento los datos del CNA 2008 quedaron seriamente comprometidos debido al subregistro que ocurrió en el 
contexto del conflicto entre el gobierno nacional y entidades agrarias en torno a las retenciones de exportación. Sin embargo, estos datos para la provincia de Mendoza presentan cierta consistencia cuando se los compara con otros relevamientos, como, por ejemplo, los datos de superficie proporcionados por el Instituto Nacional de Vitivinicultura (INV). Según el INV en 2008 existían 158.964 ha de vid en la provincia, en tanto el CNA registró 136.133 ha. Además, según el INDEC, mientras en la provincia de Buenos Aires el CNA 2008 solo registró un 65,2 \% de la superficie relevada durante el CNA 2002, en Mendoza ese porcentaje alcanzó el 134,7 \% (INDEC, 2009). Teniendo presente estas salvedades, consideramos que estos datos aún permiten realizar una aproximación para comprender las dinámicas de la horticultura en Mendoza en dicho periodo.

7 Para graficar esta tendencia, de las 1.998 EAP menos con cultivos hortícolas en el periodo 2002-2008, 1.507 pertenecían al estrato de hasta 5 ha cultivadas y 389 al estrato de entre 5,1 y 15 ha. Al momento de escritura de este artículo no se disponían de datos desagregados provenientes del CNA 2018.

8 Recuérdese, como ya introdujimos al comienzo de este artículo, que una de las formas más difundidas de aparcería en la horticultura de Mendoza establece una relación fuertemente asimétrica. Nos referimos a aquella en la cual el aparcero recibe el $30 \%$ de la producción y solo aporta la fuerza de trabajo. Bajo esta forma las partes se conocen localmente como “chacarero" y "patrón”, lo cual dice mucho de las características de la misma (Carballo e Ivars, 2018).

9 Denominación local para los cultivos hortícolas.

10 Esta clasificación se basa en el órgano de la planta destinado al consumo. Según la misma las hortalizas pueden clasificarse como hortalizas de hoja, crucíferas, pesadas y de raíz, y de flores, frutos y tallos.

11 Denominación local de las especies competidoras de los cultivos.

12 También en otros países la situación se repite como es el caso de horticultores mexicanos que como respuesta a la productividad decreciente de sus tierras han respondido aplicando más insumos industriales comprometiendo el futuro de su propia actividad (Lastra y Perales Rivera, 2007). 